\title{
Patterns of copy number alterations in primary breast tumors of South African patients and their impact on functional cellular pathways
}

\author{
KAMIL LUPICKI $^{1 *}$, SELENE ELIFIO-ESPOSITO ${ }^{2 *}$, ALINE S. FONSECA ${ }^{1}$, SAULO H. WEBER $^{3}$, \\ BRUNA SUGITA $^{4}$, BRIDGET C. LANGA ${ }^{5}$, SILMA R.F. PEREIRA ${ }^{6}$, DHIRENDRA GOVENDER ${ }^{7}$, \\ EUGENE PANIERI $^{8}$, DONAVON C. HISS ${ }^{5}$, SAHAR ABDUL-RASOOL ${ }^{5}$ and LUCIANE R. CAVALLI ${ }^{1}$
}

\footnotetext{
${ }^{1}$ Department of Oncology, Lombardi Comprehensive Cancer Center, Georgetown University, Washington DC 20007, USA;

Departments of ${ }^{2}$ Health Sciences and ${ }^{3}$ Biotechnology, Pontifícia Universidade Católica do Paraná, Curitiba, Paraná 80215-901; ${ }^{4}$ Department of Genetics, Federal University of Parana, Curitiba, Paraná 80060-000, Brazil; ${ }^{5}$ Department of Medical Biosciences, University of the Western Cape, Bellville, Western Cape 7535, South Africa;

${ }^{6}$ Department of Biology, Federal University of Maranhão, São Luis, Maranhão 65080-805, Brazil;

${ }^{7}$ Division of Anatomical Pathology, University of Cape Town, National Health Laboratory Service, Groote Schuur Hospital, Cape Town 7700; ${ }^{8}$ Department of Surgical Oncology, Groote Schuur Hospital, Cape Town 7700, South Africa
}

Received April 16, 2018; Accepted July 24, 2018

DOI: 10.3892/ijo.2018.4589

\begin{abstract}
Breast cancer is the most common and the leading cause of female mortality among South African (SA) women. Several non-biological and biological risk factors may be attributed to their observed high mortality rate; however, the molecular profiles associated with their breast tumors are poorly characterized. The present study examined the patterns of genome-wide copy number alterations (CNAs) and their potential impact on functional cellular pathways targeted by cancer driver genes in patients with breast cancer from the Western Cape region of SA. Array-comparative genomic hybridization analysis, performed in 28 cases of invasive breast cancer, revealed a mean number of $8.68 \pm 6.18$ CNAs per case, affecting primarily the Xp22.3 and 6p21-p25 cytobands (57.14\% of the cases), followed by 19p13.3-p13.11 (35.7\%), 2p25.3-p24.3, 4p16.3-p15.3, 8q11.1-q24.3 and 16 p13.3-p11.2 (32.14\%). Functional enrichment analysis of genes and microRNA targets mapped in these affected cytobands revealed critical cancer-associated pathways, including fatty acid biosynthesis and metabolism, extracellular matrix-receptor
\end{abstract}

Correspondence to: Dr Luciane R. Cavalli, Department of Oncology, Lombardi Comprehensive Cancer Center, Georgetown University, 3800 Reservoir Road, NW, Washington DC 20007, USA

E-mail: 1rc@georgetown.edu

${ }^{*}$ Contributed equally

Key words: breast cancer, South Africa (SA), copy number, genomic profiling, genomic variants interaction, hippo and tumor protein p53 signaling pathways, which are regulated by known cancer genes, including CCND1, CDKN1A, MAPK1, MDM2, TP53 and SMAD2. An inverse correlation was observed among the number of CNAs and tumor size and grade; CNAs on the $4 \mathrm{p}$ and $6 \mathrm{p}$ cytobands were also inversely correlated with tumor grade. No association was observed in the number of CNAs and/or the affected cytobands and the different ethnic groups of the SA patients, indicating that their tumor genome is affected by CNAs, irrespectively of their genetic descent. Additional genomic tumor profiling in SA and other Sub-Saharan African patients with breast cancer is required to determine the associations of the CNAs observed with prognosis and clinical outcome.

\section{Introduction}

The incidence of breast cancer continues to increase globally. According to the most recent Globocan estimates (2012), breast cancer ranks as the fifth highest cause of mortality from cancer overall, and is the most frequent cause of cancer mortalities in women in developing countries (1). In Africa, there is a substantial variation in the estimated breast cancer incidence across different regions, which may be attributed to the exposure to different environmental factors (2). South Africa (SA) presents the highest incidence of breast cancer, affecting primarily young women ( $\leq 50$ years old), who are diagnosed at a mean age of 10 years younger compared with women in Western countries. However, the mortality rates in SA remain high ( 17\%) among female populations of all ages, potentially due to the late stage of the disease at diagnosis (1). The high rates of incidence and mortality are due to multiple and complex social, cultural and economic factors that directly impact breast cancer diagnosis and response to treatment. The 
health care system in SA and other Sub-Saharan countries, in general, face inadequate health personnel, offer poor health insurance programs and limited facilities for cancer screening and treatment, and are compounded by prohibitive costs for breast biopsies and pathological exams (3). Other factors involve lifestyle-associated risks including smoking, alcohol consumption and high fat diets (4). In addition, several studies have demonstrated that in the Sub-Saharan region, including $\mathrm{SA}$, there is an over-representation of breast cancer subtypes that denote poorer prognosis, most notably among pre-menopausal women (5-9). Although the standard classification of breast cancer, based on three surrogate immunohistochemistry (IHC) markers, the estrogen (ER), progesterone (PR) and human epidermal growth factor receptor 2 (HER2) receptors, is not routinely performed in the majority of SA cancer centers, but studies have demonstrated the prevalence of hormonal negative tumor subtypes, including a high rate of triple negative breast cancer (TNBC) and HER2-positive tumor subtypes. These two subtypes are known to present a clinically aggressive phenotype, including resistance to treatment and high rates of disease recurrence (7-9). Although the determinants for the high prevalence of these unfavorable tumor subtypes is unclear, several studies implicate intrinsic genetic differences, such as the presence of founder mutations in breast cancer susceptibility genes, including the BRCAl gene (10-12) or unknown genomic variants identified by genomic wide association studies (13-16).

The extensive characterization of the molecular profiling in breast cancer with the use of multi-omics platforms, have allowed for extraordinary progress in the understanding of the biological factors and their clinical impact on each breast cancer subtype $(17,18)$. In African countries, however, they remain poorly characterized, mainly due to the unavailability and the high costs of such platforms in addition to the poor annotation of patients' clinical data (19). Among the African countries, SA has the highest number of published genomic research studies (assessed between 2004-2013), however only $6.1 \%$ of these studies are associated with cancer (20). To the best of our knowledge, few breast cancer studies have characterized patient genomic profiles and/or specific molecular alterations in their populations (14,21-25). As a consequence, there is limited knowledge on their tumor biology and the corresponding lack of clinically relevant biomarkers that would be particularly beneficial for the prognosis and treatment of patients with breast cancer representative of the diverse racial groups of SA.

The integrity of the genome is crucial for tumor suppression. Genomic instability, one of the hallmarks of cancer, can be evidenced by the presence of DNA copy number changes $(26,27)$. The presence of gains and losses in specific cytobands of chromosomes is a clear evidence of loss of the genomic integrity control cancers (28). The recurrence of these specific alterations, which may affect the function of cancer driver genes mapped in these regions, including oncogenes and tumor suppressors, occurs during tumor progression and may also facilitate this process (29).

In the present study, the main aim was to determine the patterns of the genome-wide copy number alterations (CNAs) and their potential impact on functional cellular pathways targeted by cancer driver genes in patients with breast cancer from the Western Cape region of SA. This study further assessed the correlations between the genomic results with the patients clinicopathological data. In addition, considering the extensive genetic diversity of the SA population, composed of groups originating from Europe, Asia and various African countries, the present study also aimed to determine whether the main copy number patterns observed were associated with patient's ethnicity.

\section{Materials and methods}

Sample population. Formalin-fixed paraffin-embedded (FFPE) breast tumor specimens were obtained from 28 female patients from the archives of the Division of Anatomical Pathology, National Health Laboratory Services, Groote Schuur Hospital (Cape Town, SA). These cases were obtained retrospectively between 2006 and 2010 with ethical approval from the Groote Schuur Hospital (Human Research Ethics Committee protocol no. 454/2010); patient identities were kept anonymous at all stages of the study. The specimens were collected at diagnosis and prior to any cancer treatment. The clinical data pertaining to age, ethnicity, tumor stage and receptor status were obtained for each patient. The mean age of the study population at diagnosis was $48.2 \pm 12.9$ years, ranging from 22 to 80 years old. All cases were of infiltrating ductal carcinoma and the mean tumor size was $40.6 \pm 18.9 \mathrm{~mm}$. Tumor types were classified according to the Tumor Node Metastasis staging system (30) and were of grade 1,2 and 3 in 16\%,44\%, and $40 \%$ of the cases, respectively. Stages I, II and III were observed in $7.4 \%, 22.2 \%$, and $70.4 \%$ of the cases, respectively. The cases were evaluated for ER, PR and HER2 receptor status by IHC, as previously described $(31,32)$. ER and HER2 positivity was observed in $57.1 \%$ and $53.8 \%$ of cases, respectively. PR status was available for only $21.4 \%$ of the patients, out of which $33 \%(2 / 6)$ were positive. Three patients were of the TNBC subtype.

Information regarding ethnicity was obtained from selfreported records. The majority of the patients were of the Colored group (57.1\%), while $21.4 \%$ were White, $17.9 \%$ were Black and 3.6\% were Asian. Based on the South African census nomenclature and definitions, these categories refer to people with common characteristics in terms of history and descent, which were mostly defined in the Apartheid period (31). The Colored group is composed of highly admixed individuals who present ancestry from Europe and Asia and various indigenous tribes of SA. They form the majority population of the Western Cape region, and genetic studies have demonstrated that they are mainly descendants of the Khoisan tribe $(31,32)$. White refers to people of European descent, mainly from the Netherlands, Germany, France and England. Black refers to individuals of African tribe origin including Zulu, Xhosa and Basotho tribes (31). The samples were not selected based on any of the clinical information and ethnicity. The main inclusion criteria, subsequent to institutional review board local approval, included patients with invasive breast cancer and with known hormonal and ERBB2 status and clinicopathological data. The distribution of the clinicopathological data and ethnic groups in the studied population is presented in Table I.

Array-comparative genomic hybridization (array-CGH) analysis. DNA copy number analysis was performed using an 


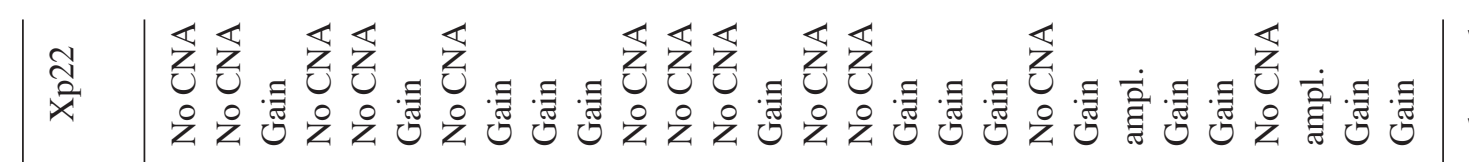

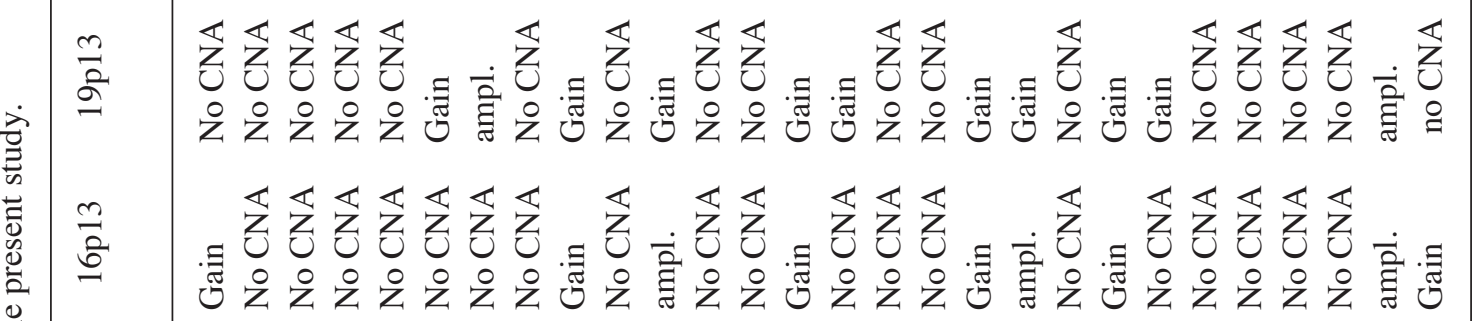

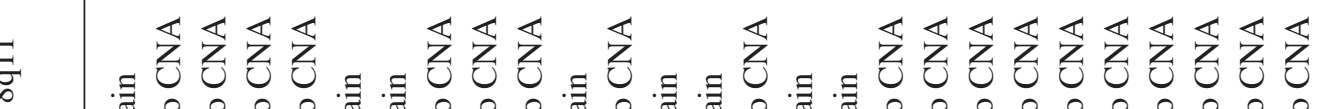

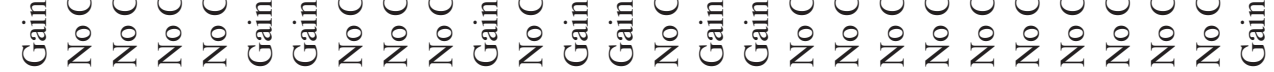

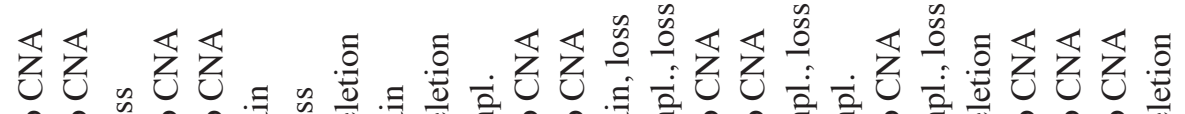
z之o

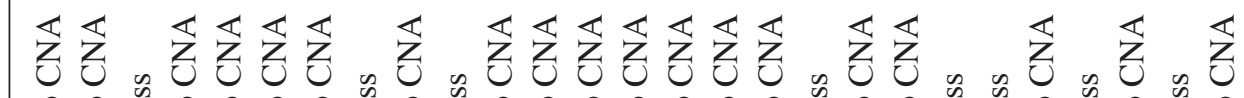

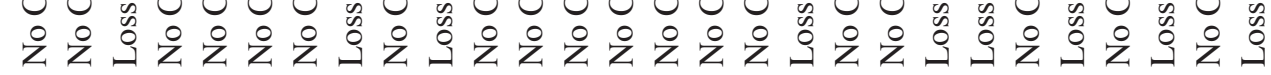

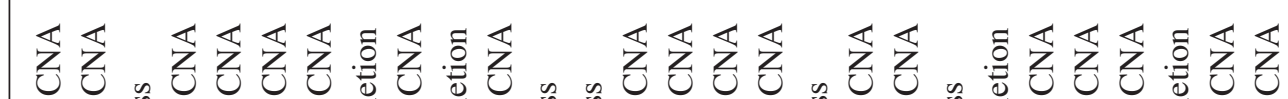

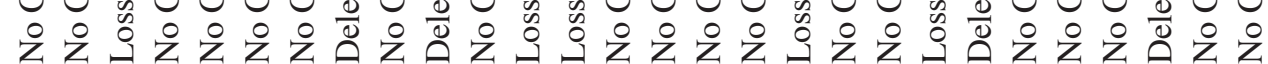

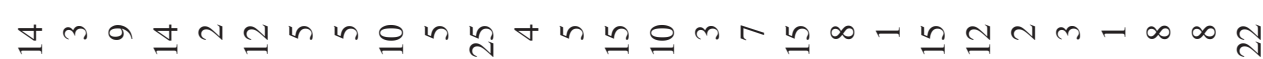

胥

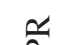

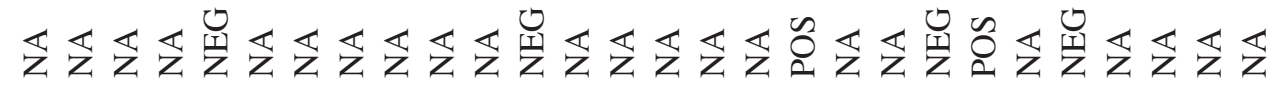

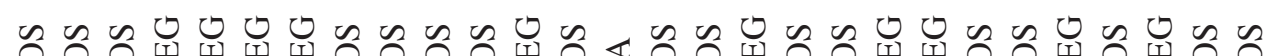

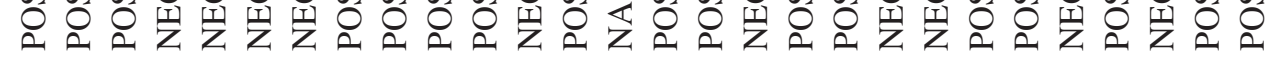

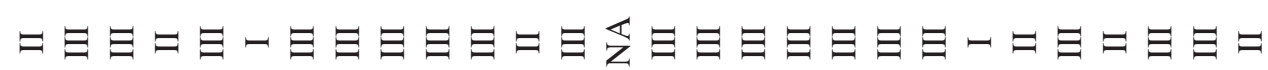

事

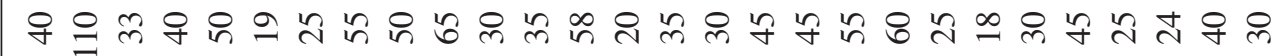
nanmmam-

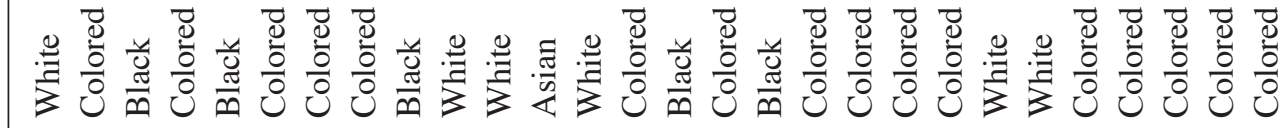
苛 요 


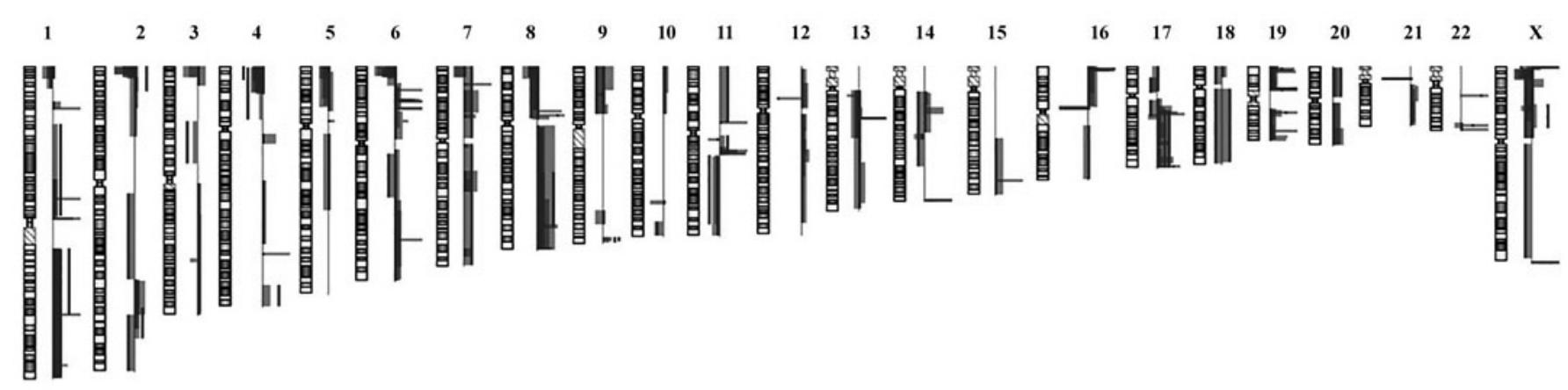

Figure 1. Array-CGH genomic view of the 28 South African patients with breast cancer. The vertical blue lines (CytoGenomics v.3.0) indicate the copy number alterations observed: lines to the left of the chromosome indicate losses and to the right gains of copy number.

oligonucleotide array-CGH platform (SurePrint G3 Human CGH Microarray 8x60K; Agilent Technologies Inc., Santa Clara, CA, USA), according to the protocol for FFPE samples that were established as previously described $(33,34)$. Prior to DNA isolation, 5- $\mu \mathrm{m}$ sections of FFPE tissue from each case were evaluated by a pathologist from the Division of Anatomical Pathology, University of Cape Town (National Health Laboratory Service, Groote Schuur Hospital, Cape Town), to confirm the tumor histopathology and the presence of breast epithelial cancer cells. These cells were identified and microdissected in tissue sections that were $5 \mu \mathrm{m}$ thick from consecutive unstained slides to ensure the array-CGH analysis of a pure tumor cell population. DNA was isolated using the standard phenol-chlorophorm method as was previously described (32). Normal (reference) DNA was prepared from the peripheral blood of a pool of multiple healthy female donors, as previously described $(35,36)$. Equal amounts of tumor and reference genomic DNA (300-500 ng) were digested and enzymatically labeled using the SureTag Complete DNA Labeling kit (Agilent Technologies, Inc.) and hybridized to the arrays, according to the manufacture's protocols. The array data was analyzed using the Feature Extraction v.10.10 and Agilent Cytogenomics v.3.0 software (Agilent Technologies Inc.), (ADM) after aberration detection method-2 algorithm, a threshold of 6.0 and an aberration filter with a minimum number of $>3$ probes. Copy number gains and losses were defined as previously described (34): Minimum mean absolute $\log _{2}$ ratio [intensity of the Cy5 dye (reference DNA)/intensity of the $\mathrm{Cy} 3$ dye (test DNA) value] of $\geq 0.25$ and $\leq-0.25$, respectively, as per the array-CGH analytics analysis. Amplifications and deletions were determined using values of $\log _{2} \geq 2$ and $\log _{2} \leq-2$, respectively.

Functional enriched pathways. The identification of the genes and microRNAs (miRNAs) mapped in the cytobands that presented CNAs was obtained from the Agilent Cytogenomics v.7.0 (Agilent Technologies, Inc.) interval base reports (based on the analysis parameters described above). DIANA-miRPath v.3 (37) was used to perform the pathway enrichment analysis, based on the Kyoto Encyclopedia of Genes and Genomes database (37). miRNA targets were identified using TarBase v.7.0 (38). Only miRNA/mRNA targets that presented a miRNA Target Gene (miTG) score $>0.7$ based on the microT-CDS (39) interactions were included.
Correlation of CNAs with clinicopathological data and ethnicity. Spearman bivariate correlation analysis was performed to determine the association among the number of CNAs and the most frequent affected cytobands with patient clinicopathological data (age $<50$ or $\geq 50$ years, mean tumor size + and - standard deviation, tumor grades 1-3, tumor stages I-III, ER and HER2 expression status) and ethnicity. Data is presented as Spearman's correlation coefficient ( $r$ ), and $\mathrm{P}<0.05$ was considered to indicate a statistically significant difference. Statistical analysis was performed using SPSS Statistics 20 (IBM Corp., Armonk, NY, USA).

\section{Results}

DNA copy number changes. Array-CGH analysis was performed for all cases. The CNAs ranged from 1 to 25 , with a mean number of $8.68 \pm 6.18$ CNAs per case. Twelve cases presented CNAs above or equal the mean and 16 cases below. The combined genomic profile of the cases analyzed are presented in Fig. 1. The most frequent affected chromosome cytobands were Xp22.3 and 6p21-p25 (57.14\% of the cases), 19p13.3-p13.11 (35.7\%), followed by 2p25.3-p24.3, 4p16.3p15.3, 8q11.1-q24.3 and 16 p13.3-p11.2 (32.14\%) (Table I). Chromosomes $2 p$ and $4 p$ were mostly affected by losses and deletions of copy number, whereas chromosomes 8q, 16p and $\mathrm{Xp}$ by gains and amplifications, and chromosome $6 \mathrm{p}$ by gains and amplifications (mainly 6p22.2-p21) and losses/deletions (mainly 6p25-p24).

A higher number of CNAs (CNAs $\geq 8.68$ ) were significantly correlated with the cases that present with CNAs in the $6 \mathrm{p}(\mathrm{r}=0.458 ; \mathrm{P}<0.05), 16 \mathrm{p}(\mathrm{r}=0.486 ; \mathrm{P}<0.01)$ and $19 \mathrm{p}(\mathrm{r}=0.486$; $\mathrm{P}<0.01)$ cytobands. CNAs on $2 \mathrm{p}$ were significantly correlated with CNAs on $4 p(r=0.580 ; \mathrm{P}<0.001)$; CNAs on $4 \mathrm{p}$ were significantly correlated with CNAs on $6 \mathrm{p}(\mathrm{r}=0.442 ; \mathrm{P}<0.05)$ and $\mathrm{Xp}$ $(r=0.596 ; P<0.001)$; CNAs on $6 p$ were significantly correlated with CNAs on $19 \mathrm{p}(\mathrm{r}=0.697 ; \mathrm{P}<0.001)$ and $\mathrm{Xp}(\mathrm{r}=0.563$; $\mathrm{P}<0.01)$ and CNAs on $16 \mathrm{p}$ were significantly correlated with CNAs on $19 \mathrm{p}(\mathrm{r}=0.542 ; \mathrm{P}<0.01)$.

The identification of the genes mapped in these cytobands, using the Agilent Cytogenomics interval base reports, revealed a total number of 2,719 genes and 93 miRNAs (Table II). To investigate the function of these specific genes and miRNAs that may be affected by the presence of CNAs in these cytobands, pathway enrichment analysis (DIANA-miRPath v.3) was used. Among the top 15 pathways identified, based on 







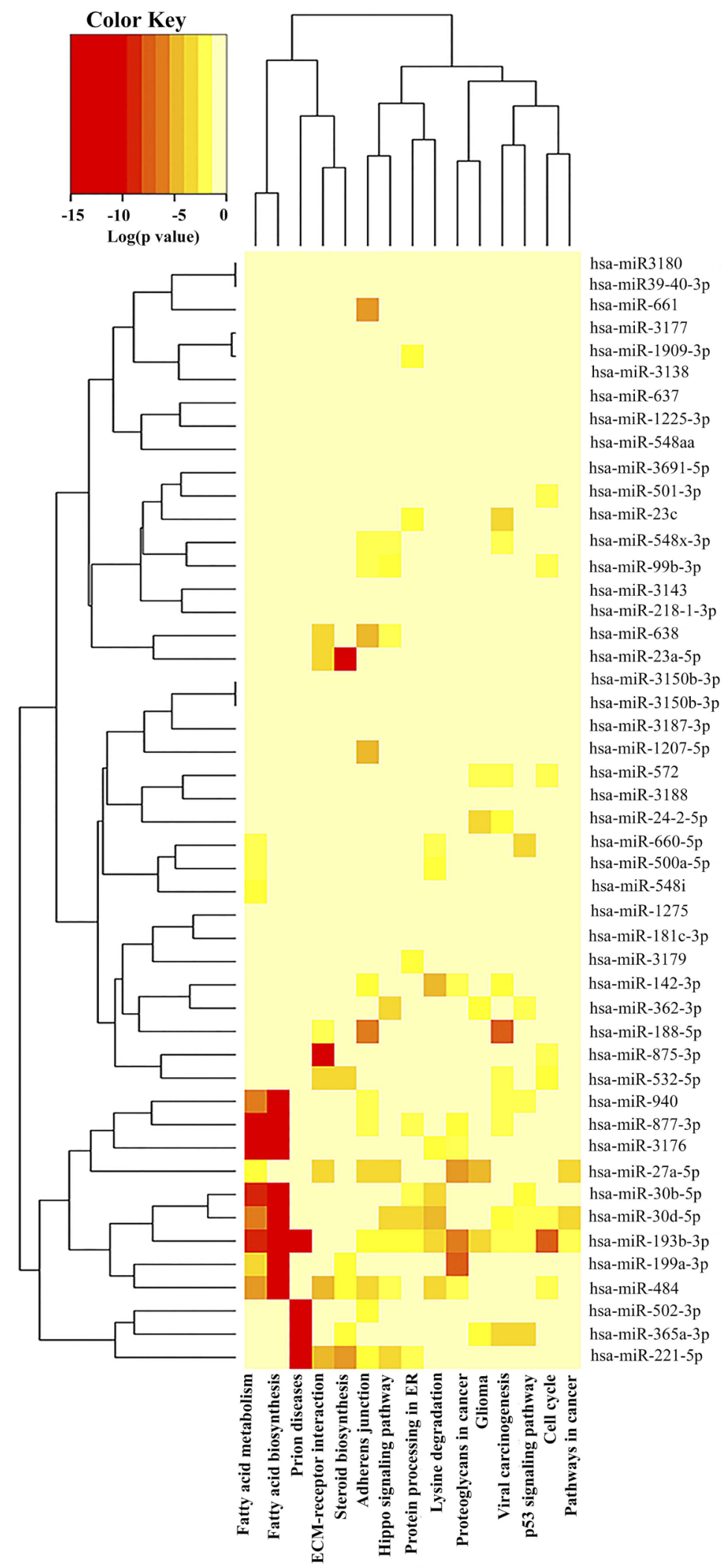

Figure 2. Targeted pathway clusters/heatmap presenting the top 15 Kyoto Encylopedia of Genes and Genomes pathways regulated by the miRNAs mapped at the cytobands most affected by CNAs in the cases studied ( $\mathrm{P}<0.05$; DIANA/mirPath v.3). miRNA/miR, microRNA; ECM, extracellular matrix; ER, endoplasmic reticulum.

P-value, were pathways associated with prion diseases, fatty acid biosynthesis and metabolism, adherens junction, extracellular matrix (ECM)-receptor interaction, hippo and tumor protein p53 (TP53) signaling pathways (Fig. 2; Table III).
Among these top pathways, the ones that were affected by the largest number of miRNAs were the adherens junctions (14 miRNAs), fatty acid metabolism and the viral carcinogenesis pathway (12 miRNAs each) (Table III). 


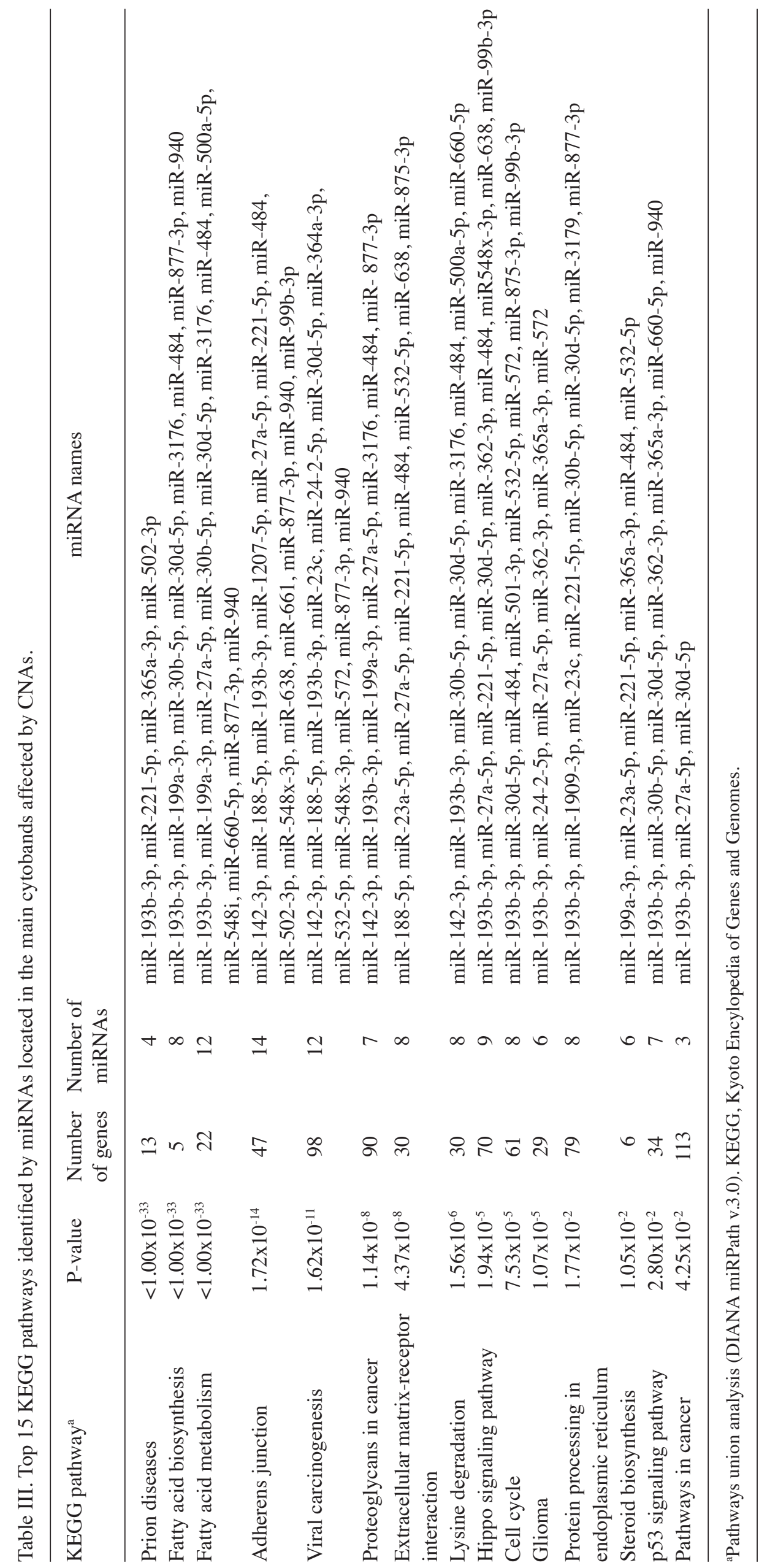




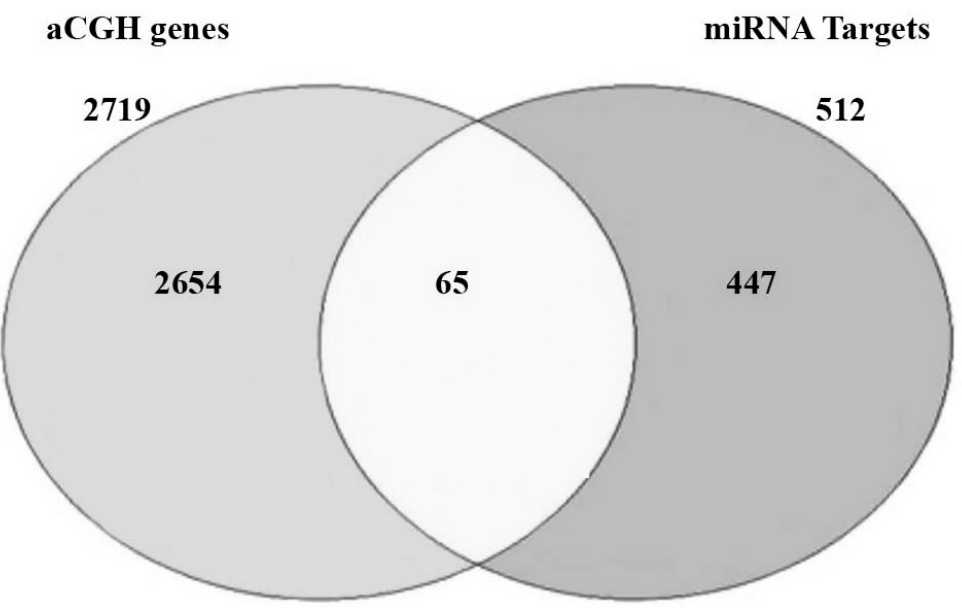

Lists contain 3166 unique elements

Figure 3. Venn diagram presenting the integration of genes located at the cytobands most affected by the copy number alterations (present in $>30 \%$ of the cases) and the target genes regulated by the miRNAs mapped at the same cytobands. miRNA, microRNA; aCGH, array CGH.

Using miRNA target prediction analysis (using TarBase v.7.0), 512 targets predicted to be regulated by these miRNAs were identified (miTG score $>0.7$ - microT-CDS interactions). A number of common miRNA targets were observed within these 15 pathways, including the cancer driver genes $C C N D 1$ in $46.7 \%$ of the pathways, CDKN1A, MAPK1 and $M D M 2$ in $40 \%, S M A D 2$ in $33.3 \%$ and CCND2, IGF1R, KRAS, SMAD3 and TP53 genes in 26.7\% (data not shown).

The integration of these miRNAs gene targets with the 2,719 genes that were mapped in the cytobands with CNAs, as generated by the Cytogenomic interval base reports (Table III), revealed a number of 65 common genes (Fig. 3). From these common genes, that may be potentially affected by copy number and miRNA expression regulation, $35.4 \%$ were mapped at the 6p25.3-p21.1 cytoband, $18.5 \%$ at 8q11.1-q24.3, 17\% at 16p13.3-p11.2 and 19p13.3-p13.11,7.7\% at

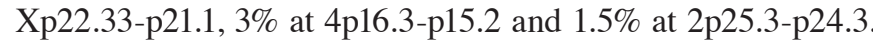
The majority of these 65 common genes were involved in viral carcinogenesis (33.8\%) and cell cycle pathways (16.9\%) (Table IV). Among these genes are known cancer driver genes, including CDKNIA, MAPKs, MYC and VEGFA.

Correlation of CNAs with clinicopathological parameters and ethnicity. Prior to the association between the clinicopathological data and ethnicity (Table I) with the copy number data, a significant correlation between tumor size and tumor stage $(r=0.532 ; \mathrm{P}<0.01)$ was observed. Inverse correlations were observed between ER status and tumor grade (ER positivity and lower tumor grade $\mathrm{r}=-0.664 ; \mathrm{P}<0.001)$ and HER2 status and tumor size $(\mathrm{r}=-0.408 ; \mathrm{P}<0.05)$. No correlation was observed among the other clinicopathological parameters and/ or the diverse ethnic groups.

For the association with the number of CNAs, the cases were divided into two groups; one with the number of CNAs higher and one lower than the mean number of CNAs observed among the cases ( $\geq 8.68$ and $<8.68$, respectively). Unpredictably, the cases in the group with a lower number of CNAs were significantly associated with higher tumor size $(\mathrm{r}=-0.401 ; \mathrm{P}<0.05)$ and tumor grade $(\mathrm{r}=-0.516 ; \mathrm{P}<0.01)$. The association of the most frequent cytobands affected with the clinicopathological parameters above, revealed correlation of CNAs on $4 p(r=-0.452 ; P<0.05)$ and $6 p(r=-0.491 ; P<0.05)$ with tumor grade. No significant association was observed among CNAs and/or specific cytobands with any ethnic group.

\section{Discussion}

Genome-wide molecular signatures are well-defined and established in breast cancer, characterizing the distinct intrinsic subtypes and their impact on prognosis and clinical outcome $(18,19)$. However, there are limited genomic signatures characterizing breast cancer based on the ancestry of a patient, particularly associated with their tumor somatic profiles. In patients of African descent, the majority of the studies available are based on genetic variants, including single nucleotide polymorphism and copy number variation (CNV) $(13,15,16)$. While they are relevant in determining cancer risk and susceptibility in specific populations, they fail to characterize the tumor genomic signatures and corresponding imbalances in gene dosages and mutations that are prevalent and may affect cancer genes.

CNAs in the tumor genome may result in the gain/amplification of oncogenes and/or loss/deletion of tumor suppressor genes and are major drivers of tumor development $(27,40)$. A genome-wide analysis of CNAs conducted in different types of cancer revealed that a specific tumor type presents $17 \%$ of regions with amplifications and 16\% of deletions, compared with $<0.5 \%$ in normal samples (40). The patterns of these somatic tumor alterations, as CNVs, may also vary within ethnic groups $(35,41)$. The majority of the studies assessing these alterations, in addition to their gene and epigenetic expression profiles, are in White European and African American patients with breast cancer (35,40-45). Few studies have been performed in patients from Sub-Saharan countries $(24,25)$. Thus, the consequences of CNAs due to the genetic instability of their tumor types remain largely unknown.

In the present study, genome-wide copy number profiling in patients with breast cancer patients from the Western 
Table IV. Common genes targeted by microRNAs and copy number alterations in the main affected cytobands and their corresponding involvement in signaling pathways.

\begin{tabular}{|c|c|c|}
\hline Genes name & Chromosome & Kyoto Encylopedia of Genes and Genomes Pathway \\
\hline$Y W H A Q$ & $2 \mathrm{p} 25.3-\mathrm{p} 24.3$ & Viral carcinogenesis; Hippo Signaling; Cell Cycle \\
\hline WFS1 & $4 \mathrm{p} 16.3-\mathrm{p} 15.2$ & Protein processing RE \\
\hline WHSC 1 & $4 \mathrm{p} 16.3-\mathrm{p} 15.2$ & Lysine degradation \\
\hline$C C N D 3$ & $6 \mathrm{p} 25.3-\mathrm{p} 21.1$ & TP53 signaling pathway; Cell Cycle; Hippo signaling \\
\hline$C D K N 1 A$ & $6 \mathrm{p} 25.3-\mathrm{p} 21.1$ & Proteoglycans in cancer; Viral Carcinogenesis; Gliomas; Cell cycle; TP53 signaling pathway \\
\hline$E 2 F 3$ & $6 \mathrm{p} 25.3-\mathrm{p} 21.1$ & Gliomas; Pathways in Cancer; Cell cycle \\
\hline HIST1H2BD & $6 \mathrm{p} 25.3-\mathrm{p} 21.1$ & Viral carcinogenesis \\
\hline HIST1H2BH & $6 \mathrm{p} 25.3-\mathrm{p} 21.1$ & Viral carcinogenesis \\
\hline HISTIH4C & $6 \mathrm{p} 25.3-\mathrm{p} 21.1$ & Viral carcinogenesis \\
\hline HIST1H4D & $6 \mathrm{p} 25.3-\mathrm{p} 21.1$ & Viral carcinogenesis \\
\hline$H L A-A$ & $6 \mathrm{p} 25.3-\mathrm{p} 21.1$ & Viral carcinogenesis \\
\hline$H L A-B$ & $6 \mathrm{p} 25.3-\mathrm{p} 21.1$ & Viral carcinogenesis \\
\hline$H L A-C$ & $6 \mathrm{p} 25.3-\mathrm{p} 21.1$ & Viral carcinogenesis \\
\hline HSP90AB1 & $6 \mathrm{p} 25.3-\mathrm{p} 21.1$ & Pathways in Cancer; Protein processing RE \\
\hline HSPAIA & $6 \mathrm{p} 25.3-\mathrm{p} 21.1$ & Protein processing RE; Prion disease \\
\hline$H S P A 1 B$ & $6 \mathrm{p} 25.3-\mathrm{p} 21.1$ & Protein processing RE \\
\hline HSPAIL & $6 \mathrm{p} 25.3-\mathrm{p} 21.1$ & Protein processing $\mathrm{RE}$ \\
\hline ITPR3 & $6 \mathrm{p} 25.3-\mathrm{p} 21.1$ & Proteoglycans in cancer \\
\hline MAPK 13 & $6 \mathrm{p} 25.3-\mathrm{p} 21.1$ & Proteoglycans in cancer \\
\hline MRPS18B & $6 \mathrm{p} 25.3-\mathrm{p} 21.1$ & Viral carcinogenesis \\
\hline$P P A R D$ & $6 \mathrm{p} 25.3-\mathrm{p} 21.1$ & Pathways in cancer \\
\hline PPT2 & $6 \mathrm{p} 25.3-\mathrm{p} 21.1$ & Fatty Acid Metabolism \\
\hline$S R F$ & $6 \mathrm{p} 25.3-\mathrm{p} 21.1$ & Viral carcinogenesis \\
\hline SSR1 & $6 \mathrm{p} 25.3-\mathrm{p} 21.1$ & Protein processing RE \\
\hline TEAD3 & $6 \mathrm{p} 25.3-\mathrm{p} 21.1$ & Hippo signaling \\
\hline VEGFA & $6 \mathrm{p} 25.3-\mathrm{p} 21.1$ & Pathways in Cancer; Proteoglycans in cancer \\
\hline CCNE2 & $8 \mathrm{q} 11.1-\mathrm{q} 24.3$ & Viral carcinogenesis; Cell cycle; TP53 signaling pathway; Pathways in cancer \\
\hline FZD6 & $8 \mathrm{q} 11.1-\mathrm{q} 24.3$ & Proteoglycans in cancer; Hippo Signaling \\
\hline$L Y N$ & $8 \mathrm{q} 11.1-\mathrm{q} 24.3$ & Viral carcinogenesis \\
\hline MCM4 & $8 \mathrm{q} 11.1-\mathrm{q} 24.3$ & Cell cycle \\
\hline$M Y C$ & $8 \mathrm{q} 11.1-\mathrm{q} 24.3$ & Hippo Signaling; Pathways in cancer; Cell cycle \\
\hline$P R K D C$ & $8 \mathrm{q} 11.1-\mathrm{q} 24.3$ & Cell cycle \\
\hline$P T K 2$ & $8 \mathrm{q} 11.1-\mathrm{q} 24.3$ & Proteoglycans in cancer; Pathways in cancer \\
\hline$R A D 21$ & $8 \mathrm{q} 11.1-\mathrm{q} 24.3$ & Cell cycle \\
\hline$R R M 2 B$ & $8 \mathrm{q} 11.1-\mathrm{q} 24.3$ & TP53 signaling pathway; \\
\hline$S C R I B$ & $8 \mathrm{q} 11.1-\mathrm{q} 24.3$ & Viral carcinogenesis; Hippo Signaling \\
\hline$S Q L E$ & $8 q 11.1-q 24.3$ & Steroid Biosynthesis \\
\hline$Y W H A Z$ & $8 \mathrm{q} 11.1-\mathrm{q} 24.3$ & Viral carcinogenesis; Hippo Signaling \\
\hline$A D C Y 9$ & $16 \mathrm{p} 13.3-\mathrm{p} 11.2$ & Pathways in cancer \\
\hline AXIN1 & $16 \mathrm{p} 13.3-\mathrm{p} 11.2$ & Hippo signaling \\
\hline$C R E B B P$ & 16p13.3-p11.2 & Adherens in junction; Viral carcinogenesis \\
\hline$D N A J A 3$ & $16 \mathrm{p} 13.3-\mathrm{p} 11.2$ & Viral carcinogenesis \\
\hline MAPK3 & $16 \mathrm{p} 13.3-\mathrm{p} 11.2$ & Prion disease; Adherens in junction; Proteoglycans in cancer; Gliomas; Pathways in cancer \\
\hline PKMYT1 & $16 \mathrm{p} 13.3-\mathrm{p} 11.2$ & Cell cycle \\
\hline PLK1 & $16 \mathrm{p} 13.3-\mathrm{p} 11.2$ & Cell cycle \\
\hline$P R K C B$ & $16 \mathrm{p} 13.3-\mathrm{p} 11.2$ & Proteoglycans in cancer; Gliomas \\
\hline SETD1A & $16 \mathrm{p} 13.3-\mathrm{p} 11.2$ & Lysine degradation \\
\hline TFAP4 & $16 \mathrm{p} 13.3-\mathrm{p} 11.2$ & Proteoglycans in cancer \\
\hline USP7 & 16 p13.3-p11.2 & Viral carcinogenesis \\
\hline$D N A J B 1$ & 19p13.3-p13.11 & Protein processing $\mathrm{RE}$ \\
\hline DOT1L & 19p13.3-p13.11 & Lysine degradation \\
\hline$F Z R 1$ & 19p13.3-p13.11 & Cell cycle \\
\hline
\end{tabular}


Table IV. Continued.

\begin{tabular}{lll}
\hline Genes name & Chromosome & Kyoto Encylopedia of Genes and Genomes Pathway \\
\hline INSR & $19 \mathrm{p} 13.3-\mathrm{p} 13.11$ & Adherens in junction \\
$J A K 3$ & $19 \mathrm{p} 13.3-\mathrm{p} 13.11$ & Viral carcinogenesis \\
$M A P 2 K 2$ & $19 \mathrm{p} 13.3-\mathrm{p} 13.11$ & Gliomas \\
$M A P 2 K 7$ & $19 \mathrm{p} 13.3-\mathrm{p} 13.11$ & Protein processing RE \\
$P I K 3 R 2$ & $19 \mathrm{p} 13.3-\mathrm{p} 13.11$ & Proteoglycans in cancer; Viral Carcinogenesis \\
$P R K A C A$ & $19 \mathrm{p} 13.3-\mathrm{p} 13.11$ & Prion Disease; Viral Carcinogenesis \\
$P R K C S H$ & $19 \mathrm{p} 13.3-\mathrm{p} 13.11$ & Protein processing RE \\
$T E C R$ & $19 \mathrm{p} 13.3-\mathrm{p} 13.11$ & Fatty acid metabolism \\
$D D X 3 X$ & $\mathrm{Xp} 22.33-\mathrm{p} 21.1$ & Viral carcinogenesis \\
$M B T P S 2$ & $\mathrm{Xp} 22.33-\mathrm{p} 21.1$ & Protein processing RE \\
$P R K X$ & $\mathrm{Xp} 22.33-\mathrm{p} 21.1$ & Prion disease \\
$S M C 1 A$ & $\mathrm{Xp} 22.33-\mathrm{p} 21.1$ & Viral carcinogenesis; Hippo Signaling \\
$U B Q L N 2$ & $\mathrm{Xp} 22.33-\mathrm{p} 21.1$ & Protein processing RE \\
\hline
\end{tabular}

RE, reticulum endoplasmic; TP53, tumor protein p53.

Cape region of SA was performed. Array-CGH analysis revealed recurrent CNAs in the cases analyzed, with the most frequent affecting the cytobands 2p25.3-p24.3, 4p16.3-p15.3, 6p25.3-p22.3, 6p22.3-p.21.1, 8q11.1-q24.3, 16p13.3-p11.2, 19p13.3-p13.11 and Xp22.3. A number of these CNAs, including gains on $8 \mathrm{q}$ and $16 \mathrm{p}$, are commonly reported in breast cancer, and are not necessarily associated with specific tumor subtypes and/or ethnicity (18). A number of reports, however, have demonstrated that patients with TNBC and other $B R C A 1$-associated tumor types, which are frequently identified in women of African descent $(46,47)$, present a significantly higher frequency of focal amplifications on $8 \mathrm{q} 24$, where $C-M Y C$ is located (48). This amplification was, however, not a distinguishing characteristic associated with ancestry, as it was observed both in patients of European and African-American descent (18).

Interestingly, losses on 2p, 4p and gains on $6 \mathrm{p}, 8 \mathrm{q}, 16 \mathrm{p}$ and $19 \mathrm{p}$ were previously reported in the array-CGH analysis of a set of 28 breast cancer cases from patients from Sub-Saharan Africa (24). Among these alterations, gains on 6p presented a significant higher level of copy number increase when compared to American patients with breast cancer, previously analyzed (49). In a previous study in African-American (AA) and Non-Hispanic White patients (NHW) patients with breast cancer (35), it was observed that in the AA group there was a higher frequency of copy number gains, affecting $6 \mathrm{p}$ and $8 \mathrm{q}$, when compared with the NHW group. However, in these cases, a significant higher level of genome-wide CNAs was observed in the AA group, which may justify the observed increased in the copy number in these chromosome regions. In fact, CNAs were the only significantly different variable between AA and NHW patients with TNBC tumor subtypes $(\mathrm{P}<0.01)$ when clinicopathological parameters were taken into account (35).

A direct correlation was observed among the total number of CNAs and the main cytobands observed; a higher number of CNAs were significantly correlated with the cases that presented with CNAs in the 6p, 16p and 19p cytobands. Direct correlations were observed among CNAs on 2p, 4p, 6p, 16p, $16 \mathrm{p}$ and $\mathrm{Xp}$. No inverse correlations among the main cytobands affected by CNAs were observed.

The mean number of CNAs and the specific cytobands affected were correlated with clinicopathological parameters and the diverse SA ethnic groups. Surprisingly, a negative correlation was observed between the mean number of CNAs and tumor size and grade. CNAs on the $4 p, 6 p$ and Xp cytobands were also negatively correlated with tumor grade. In general, the increase in genomic instability is associated with poor prognostic parameters (50). However, a number of observations have demonstrated that there are clonal subpopulations of tumor types, including tumor types of epithelial origin, with high levels of somatic CNAs that are associated with a potentially better prognosis (and overall survival time) compared with tumor types with intermediate levels of CNAs (50-53). This interesting observation reflects the well-known intratumor heterogeneity marked by the presence of coexisting clones with diverse genomic compositions $(52,53)$. This may explain the unexpected results of the present study, as it was observed that there were higher levels of CNAs in the aforementioned cytobands in tumor types with lower tumor grade and smaller size.

Alterations on $8 \mathrm{p}$ were significantly correlated with PR status; however, this correlation may be spurious, considering that only 6 cases presented PR status information. CNAs on chromosome $21 \mathrm{p}$ were the only ones associated with ethnicity; no other significant differences were observed between the mean number of CNAs and/or the other most commonly affected cytobands (2p, 4p, 6p, 8q, 16p, 19p and Xp) and ethnicity, indicating that these alterations occur in SA patients irrespective of their genetic descent. Furthermore, multivariate analyses revealed that no clinical or pathological variable, including age, tumor size, grade and stage, and ER, PR and ERBB2/HER2 status were significantly correlated with ethnicity of the patients. However, the comparison of the mean number of CNAs of these SA patients to the mean number of CNAs present in the AA and NHW patients of our previous 
study (35) revealed significant differences between the Black SA and AA patients $(\mathrm{P}<0.05)$, but interestingly no differences between the White SA and NHW patients $(\mathrm{P}>0.05)$, which may indicate a common European ancestry. However, when the Colored SA group of patients were compared with the AA and NHW groups, significant differences were observed $(\mathrm{P}<0.0001$ and $\mathrm{P}<0.001$, respectively), which may be resultant of the large variation in ethnicity in this particular group of patients (from Europe and Asia and various tribes of SA).

Finally, by performing functional enrichment analysis of genes and miRNA targets mapped in the cytobands most affected by CNAs, it was observed that they affected a number of critical cancer-associated pathways, including fatty acid biosynthesis and metabolism, adherens junctions, ECM-receptor interaction, hippo and TP53 signaling pathways. These pathways include a number of cancer driver genes associated with breast cancer (54), including CCND1, CDKN1A, MAPK1, MDM2, TP53 and SMAD2. A number of the pathways observed in the present study were also identified in the AA patients with breast cancer with TNBC of a previous study (35), in which a direct integration of copy number and miRNA data conducted on the same samples was performed. Remarkably, CNAs are one of the mechanisms that may result in miRNA dysregulation (55-57). In fact, 15/26 miRNAs of the miRNAs that were identified in the AA patients (of the TNBC subtype) (35) were mapped in cytobands that are frequently affected by recurrent CNAs in breast cancer, including the 6p25.3-p21.1, 8q11.1-q24.3, 16p13.3-p11.2 and 19p13.3-p13.11 similar to the present study.

In conclusion, the present study presents the pattern of copy number changes in the genome of SA patients with breast cancer and demonstrates their potential impact on critical cancer pathways associated with their tumor genomes. Additional genomic tumor profiling in SA and other Sub-Saharan patients with breast cancer in independent and larger sample size cohorts are required in order to determine the association of these alterations with their prognosis and clinical outcome, including response to therapy.

\section{Acknowledgements}

The authors would like to thank the personnel from the Division of Anatomical Pathology, National Health Laboratory Services at the Groote Schuur Hospital (Cape Town, SA) for performing the tissue sections of the cases and the Genomics and Epigenomics Shared Resource of the Lombardi Comprehensive Cancer Center for performing the washes and scanning of the array slides.

\section{Funding}

The present study was supported by The Cancer Association of South Africa (CANSA) (to Professor Sahar Abdul-Rasool and Dr Bridget C. Langa). Scholarships to Dr Bruna Sugita and Professor Silma R.F. Pereira were provided by Coordenação de Aperfeiçoamento de Pessoal de Nível Superior, (CAPES) and the scholarship to Dr Aline S. Fonseca was provided by Conselho Nacional de Desenvolvimento Científico e Tecnológico (CNPq). Additionally, the Genomics and Epigenomics Shared Resource of the Lombardi Comprehensive
Cancer Center partially supported the present study (grant no. P30-CA051008).

\section{Availability of data and materials}

The datasets used and/or analyzed during the current study are available from the corresponding author on reasonable request.

\section{Authors' contributions}

KL performed the experiments. SEE performed data analysis and wrote the manuscript. ASF assisted in the data analysis. SHW verified the statistical analysis. BS assisted in the data analysis. BCL contributed to the initial design of the study. SRFP contributed to the initial design of the study. DG performed the pathological analysis of the cases. EP provided the specimens and clinical data. DH and SAR contributed to scientific discussions and revised the final copy of the manuscript for intellectual content. LRC designed the study and conducted the final editing of the manuscript. All authors read and approved the manuscript.

\section{Ethics approval and consent to participate}

The present study was approved by the Human Research Ethics Committee (HREC 454/2010) of the Groote Schuur Hospital (Cape Town, SA). The analysis of the human samples used in the present study was performed following the international and national regulations in accordance with the Declaration of Helsinki.

\section{Patient consent for publication}

Not applicable.

\section{Competing interests}

The authors declare that they have no competing interests.

\section{Referenes}

1. Ferlay J, Soerjomataram I, Dikshit R, Eser S, Mathers C, Rebelo M, Parkin DM, Forman D and Bray F: Cancer incidence and mortality worldwide: Sources, methods and major patterns in GLOBOCAN 2012. Int J Cancer 136: E359-E386, 2015.

2. Brinton LA, Figueroa JD, Awuah B, Yarney J, Wiafe S, Wood SN, Ansong D, Nyarko K, Wiafe-Addai B and Clegg-Lamptey JN: Breast cancer in Sub-Saharan Africa: Opportunities for prevention. Breast Cancer Res Treat 144: 467-478, 2014.

3. Tetteh DA and Faulkner SL: Sociocultural factors and breast cancer in sub-Saharan Africa: Implications for diagnosis and management. Wom Health Lond 12: 147-156, 2016.

4. Wu S, Powers S, Zhu W and Hannun YA: Substantial contribution of extrinsic risk factors to cancer development. Nature 529: 43-47, 2016

5. Bird PA, Hill AG and Houssami N: Poor hormone receptor expression in East African breast cancer: Evidence of a biologically different disease? Ann Surg Oncol 15: 1983-1988, 2008.

6. Huo D, Ikpatt F, Khramtsov A, Dangou JM, Nanda R, Dignam J, Zhang B, Grushko T, Zhang C, Oluwasola O, et al: Population differences in breast cancer: Survey in indigenous African women reveals over-representation of triple-negative breast cancer. J Clin Oncol 27: 4515-4521, 2009.

7. Ly M, Antoine M, André F, Callard P, Bernaudin JF and Diallo DA: Breast cancer in Sub-Saharan African women: Review. Bull Cancer 98: 797-806, 2011 (In French). 
8. Ly M, Antoine M, Dembélé AK, Levy P, Rodenas A, Touré BA, Badiaga Y, Dembélé BK, Bagayogo DC, Diallo YL, et al: High incidence of triple-negative tumors in sub-saharan Africa: A prospective study of breast cancer characteristics and risk factors in Malian women seen in a Bamako university hospital. Oncology 83: 257-263, 2012.

9. Galukande M, Wabinga H, Mirembe F, Karamagi C and Asea A: Molecular breast cancer subtypes prevalence in an indigenous Sub Saharan African population. Pan Afr Med J 17: 249, 2014.

10. Reeves MD, Yawitch TM, van der Merwe NC, van den Berg HJ, Dreyer G and van Rensburg EJ: BRCA1 mutations in South African breast and/or ovarian cancer families: Evidence of a novel founder mutation in Afrikaner families. Int J Cancer 110: 677-682, 2004

11. van der Merwe NC, Hamel N, Schneider SR, Apffelstaedt JP, Wijnen JT and Foulkes WD: A founder BRCA2 mutation in non-Afrikaner breast cancer patients of the Western Cape of South Africa. Clin Genet 81: 179-184, 2012.

12. Fackenthal JD, Zhang J, Zhang B, Zheng Y, Hagos F, Burrill DR, Niu Q, Huo D, Sveen WE, Ogundiran T, et al: High prevalence of BRCA1 and BRCA2 mutations in unselected Nigerian breast cancer patients. Int J Cancer 131: 1114-1123, 2012.

13. Zheng Y, Ogundiran TO, Falusi AG, Nathanson KL, John EM, Hennis AJ, Ambs S, Domchek SM, Rebbeck TR, Simon MS, et al: Fine mapping of breast cancer genome-wide association studies loci in women of African ancestry identifies novel susceptibility markers. Carcinogenesis 34: 1520-1528, 2013.

14. Francies FZ, Wainstein T, De Leeneer K, Cairns A, Murdoch M, Nietz S, Cubasch H, Poppe B, Van Maerken T, Crombez B, et al: BRCA1, BRCA2 and PALB2 mutations and CHEK2 c.1100delC in different South African ethnic groups diagnosed with premenopausal and/or triple negative breast cancer. BMC Cancer 15: 912, 2015.

15. Couch FJ, Kuchenbaecker KB, Michailidou K, MendozaFandino GA, Nord S, Lilyquist J, Olswold C, Hallberg E, Agata S, Ahsan $\mathrm{H}$, et al: Identification of four novel susceptibility loci for oestrogen receptor negative breast cancer. Nat Commun 7: 11375, 2016.

16. Huo D, Feng Y, Haddad S, Zheng Y, Yao S, Han YJ, Ogundiran TO, Adebamowo C, Ojengbede O, Falusi AG, et al: Genome-wide association studies in women of African ancestry identified 3q26.21 as a novel susceptibility locus for oestrogen receptor negative breast cancer. Hum Mol Genet 25: 4835-4846, 2016.

17. Network CGA; Cancer Genome Atlas Network: Comprehensive molecular portraits of human breast tumours. Nature 490: 61-70, 2012.

18. Ciriello G, Gatza ML, Beck AH, Wilkerson MD, Rhie SK, Pastore A, Zhang H, McLellan M, Yau C, Kandoth C, et al, TCGA Research Network: Comprehensive molecular portraits of invasive lobular breast cancer. Cell 163: 506-519, 2015.

19. Basro S and Apffelstaedt JP: Breast cancer in young women in a limited-resource environment. World J Surg 34: 1427-1433, 2010

20. Adedokun BO, Olopade CO and Olopade OI: Building local capacity for genomics research in Africa: Recommendations from analysis of publications in Sub-Saharan Africa from 2004 to 2013. Glob Health Action 9: 31026, 2016.

21. Sjögren S, Inganäs $M$, Norberg $T$, Lindgren $A$, Nordgren $H$, Holmberg L and Bergh J: The p53 gene in breast cancer: Prognostic value of complementary DNA sequencing versus immunohistochemistry. J Natl Cancer Inst 88: 173-182, 1996.

22. Sluiter M, Mew S and van Rensburg EJ: PALB2 sequence variants in young South African breast cancer patients. Fam Cancer 8: 347-353, 2009.

23. van Bogaert LJ: Breast cancer molecular subtypes as identified by immunohistochemistry in South African black women. Breast J 19: 210-211, 2013.

24. Ly M, Valent A, Diallo G, Penault-Lorca F, Dumke K, Marty V, Viehl P, Lazar V, Job B, Richon C, et al: Gene copy number variations in breast cancer of Sub-Saharan African women. Breast 22: 295-300, 2013.

25. Langa BC, Oliveira MM, Pereira SR, Lupicki K, Marian C, Govender D, Panieri E, Hiss D, Cavalli IJ, Abdul-Rasool S, et al: Copy number analysis of the DLX4 and ERBB2 genes in South African breast cancer patients. Cytogenet Genome Res 146: 195-203, 2015.

26. Hanahan D and Weinberg RA: The hallmarks of cancer. Cell 100: 57-70, 2000.

27. Hanahan D and Weinberg RA: Hallmarks of cancer: The next generation. Cell 144: 646-674, 2011.
28. Negrini S, Gorgoulis VG and Halazonetis TD: Genomic instability - an evolving hallmark of cancer. Nat Rev Mol Cell Biol 11: 220-228, 2010.

29. Korkola J and Gray JW: Breast cancer genomes - form and function. Curr Opin Genet Dev 20: 4-14, 2010.

30. Cancer A-AJCo: Cancer Staging Manual. Society AC (ed). Springer, 2002.

31. de Wit E, Delport W, Rugamika CE, Meintjes A, Möller M, van Helden PD, Seoighe C and Hoal EG: Genome-wide analysis of the structure of the South African coloured population in the Western Cape. Hum Genet 128: 145-153, 2010.

32. Quintana-Murci L, Harmant C, Quach H, Balanovsky O, Zaporozhchenko V, Bormans C, van Helden PD, Hoal EG and Behar DM: Strong maternal Khoisan contribution to the South African coloured population: A case of gender-biased admixture. Am J Hum Genet 86: 611-620, 2010.

33. Santos SC, Cavalli IJ, Ribeiro EM, Urban CA, Lima RS, BleggiTorres LF, Rone JD, Haddad BR and Cavalli LR: Patterns of DNA copy number changes in sentinel lymph node breast cancer metastases. Cytogenet Genome Res 122: 16-21, 2008.

34. Torresan C, Oliveira MM, Pereira SR, Ribeiro EM, Marian C, Gusev Y, Lima RS, Urban CA, Berg PE, Haddad BR, et al: Increased copy number of the DLX4 homeobox gene in breast axillary lymph node metastasis. Cancer Genet 207: 177-187, 2014.

35. Sugita B, Gill M, Mahajan A, Duttargi A, Kirolikar S, Almeida R, Regis K, Oluwasanmi OL, Marchi F, Marian C, et al: Differentially expressed miRNAs in triple negative breast cancer between African-American and non-Hispanic white women. Oncotarget 7: 79274-79291, 2016.

36. Cavalli LR, Man YG, Schwartz AM, Rone JD, Zhang Y, Urban CA, Lima RS, Haddad BR and Berg PE: Amplification of the BP1 homeobox gene in breast cancer. Cancer Genet Cytogenet 187: 19-24, 2008.

37. Vlachos IS, Kostoulas N, Vergoulis T, Georgakilas G, Reczko M, Maragkakis M, Paraskevopoulou MD, Prionidis K, Dalamagas T and Hatzigeorgiou AG: DIANA miRPath v.2.0: Investigating the combinatorial effect of microRNAs in pathways. Nucleic Acids Res 40W: W498-W504, 2012.

38. Vlachos IS, Paraskevopoulou MD, Karagkouni D, Georgakilas G, Vergoulis T, Kanellos I, Anastasopoulos IL, Maniou S, Karathanou $\mathrm{K}$, Kalfakakou D, et al: DIANA-TarBase v7.0: indexing more than half a million experimentally supported miRNA:mRNA interactions. Nucleic Acids Res 43D: D153-D159, 2015.

39. Paraskevopoulou MD, Georgakilas G, Kostoulas N, Vlachos IS, Vergoulis T, Reczko M, Filippidis C, Dalamagas T and Hatzigeorgiou AG: DIANA-microT web server v5.0: Service integration into miRNA functional analysis workflows. Nucleic Acids Res 41W: W169-W173, 2013.

40. Beroukhim R, Mermel CH, Porter D, Wei G, Raychaudhuri S, Donovan J, Barretina J, Boehm JS, Dobson J, Urashima M, et al: The landscape of somatic copy-number alteration across human cancers. Nature 463: 899-905, 2010.

41. Loo LW, Wang Y, Flynn EM, Lund MJ, Bowles EJ, Buist DS, Liff JM, Flagg EW, Coates RJ, Eley JW, et al: Genome-wide copy number alterations in subtypes of invasive breast cancers in young white and African American women. Breast Cancer Res Treat 127: 297-308, 2011.

42. Field LA, Love B, Deyarmin B, Hooke JA, Shriver CD and Ellsworth RE: Identification of differentially expressed genes in breast tumors from African American compared with Caucasian women. Cancer 118: 1334-1344, 2012.

43. Sturtz LA, Melley J, Mamula K, Shriver CD and Ellsworth RE: Outcome disparities in African American women with triple negative breast cancer: A comparison of epidemiological and molecular factors between African American and Caucasian women with triple negative breast cancer. BMC Cancer 14: 62, 2014.

44. Keenan T, Moy B, Mroz EA, Ross K, Niemierko A, Rocco JW, Isakoff S, Ellisen LW and Bardia A: Comparison of the genomic landscape between primary breast cancer in African American versus white women and the association of racial differences with tumor recurrence. J Clin Oncol 33: 3621-3627, 2015.

45. Ademuyiwa FO, Tao Y, Luo J, Weilbaecher K and Ma CX: Differences in the mutational landscape of triple-negative breast cancer in African Americans and Caucasians. Breast Cancer Res Treat 161: 491-499, 2017.

46. Zhang J, Fackenthal JD, Zheng Y, Huo D, Hou N, Niu Q, Zvosec C, Ogundiran TO, Hennis AJ, Leske MC, et al: Recurrent BRCA 1 and BRCA 2 mutations in breast cancer patients of African ancestry. Breast Cancer Res Treat 134: 889-894, 2012. 
47. Churpek JE, Walsh T, Zheng Y, Moton Z, Thornton AM, Lee MK Casadei S, Watts A, Neistadt B, Churpek MM, et al: Inherited predisposition to breast cancer among African American women. Breast Cancer Res Treat 149: 31-39, 2015.

48. Rodriguez-Pinilla SM, Jones RL, Lambros MB, Arriola E, Savage K, James M, Pinder SE and Reis-Filho JS: MYC amplification in breast cancer: A chromogenic in situ hybridisation study. J Clin Pathol 60: 1017-1023, 2007.

49. Andre F, Job B, Dessen P, Tordai A, Michiels S, Liedtke C, Richon C, Yan K, Wang B, Vassal G, et al: Molecular characterization of breast cancer with high-resolution oligonucleotide comparative genomic hybridization array. Clin Cancer Res 15 441-451, 2009.

50. Andor N, Maley CC and Ji HP: Genomic instability in cancer: Teetering on the limit of tolerance. Cancer Res 77: 2179-2185, 2017.

51. Birkbak NJ, Eklund AC, Li Q, McClelland SE, Endesfelder D, Tan P, Tan IB, Richardson AL, Szallasi Z and Swanton C: Paradoxical relationship between chromosomal instability and survival outcome in cancer. Cancer Res 71: 3447-3452, 2011.

52. Mroz EA, Tward AD, Hammon RJ, Ren Y and Rocco JW: Intra-tumor genetic heterogeneity and mortality in head and neck cancer: Analysis of data from the Cancer Genome Atlas. PLoS Med 12: e1001786, 2015.
53. Andor N, Graham TA, Jansen M, Xia LC, Aktipis CA, Petritsch C, Ji HP and Maley CC: Pan-cancer analysis of the extent and consequences of intratumor heterogeneity. Nat Med 22: 105-113, 2016.

54. Rajendran BK and Deng CX: Characterization of potential driver mutations involved in human breast cancer by computational approaches. Oncotarget 8: 50252-50272, 2017.

55. Calin GA, Sevignani C, Dumitru CD, Hyslop T, Noch E, Yendamuri S, Shimizu M, Rattan S, Bullrich F, Negrini M, et al: Human microRNA genes are frequently located at fragile sites and genomic regions involved in cancers. Proc Natl Acad Sci USA 101: 2999-3004, 2004.

56. Calin GA and Croce CM: MicroRNAs and chromosomal abnormalities in cancer cells. Oncogene 25: 6202-6210, 2006.

57. Zhang L, Huang J, Yang N, Greshock J, Megraw MS, Giannakakis A, Liang S, Naylor TL, Barchetti A, Ward MR, et al: microRNAs exhibit high frequency genomic alterations in human cancer. Proc Natl Acad Sci USA 103: 9136-9141, 2006. 